\title{
Evaluation of the effect of treatment on movement disorders in astrocytomas of the basal ganglia and the thalamus
}

\author{
Joachim K Krauss, Dieter F Braus, Mohsen Mohadjer, Fritz Nobbe, Fritz Mundinger
}

\begin{abstract}
Twenty patients with movement disorders associated with astrocytomas (grade I-IV according to the WHO tumour classification) of the basal ganglia and the thalamus were evaluated for the effects of treatment. Five patients had more than one movement disorder when the histological diagnosis was verified by stereotactic biopsy. Twelve had tremors, eight hemidystonia, three hemichorea, and one hemichorea/ballismus, and myoclonus respectively. Ten patients died during the follow up period, and for the surviving patients follow up periods ranged from 6-21 years. The movement disorders changed over long periods of time related to therapeutic interventions. CSF shunt operations and percutaneous radiotherapy had no definite effect on the movement disorders. There was a moderate response to medical treatment in a few patients. Stereotactic aspiration of tumour cysts had a marked influence on the movement disorder in two patients, and functional stereotactic surgery abolished tumour induced tremor in one. Interstitial radiotherapy was performed in fifteen patients for treatment of the underlying neoplasm and resulted in different and variable alterations of the movement disorders. These differences may be explained by complex interactions involving structures affected primarily by the tumour, as well as by secondary functional lesions of adjacent structures.
\end{abstract}

$(\mathcal{F}$ Neurol Neurosurg Psychiatry 1993;56:1113-1118)

Freiburg

F Nobbe

Department of

Stereotaxy and

Neuronuclear

Medicine

M Mohadjer

Zentralinstitut für

Seelische Gesundheit

Mannheim

D F Braus

St. Josefs-

Krankenhaus,

Freiburg, Germany

F Mundinger

Correspondence to:

Dr Krauss,

Neurochirurgische

Universitätsklinik,

Hugstetter Str 55, D-7800

Freiburg, Germany.

Received 2 September 1992

and in final revised form

11 December 1992

Accepted 18 December 1992 been documented only rarely in patients with MDs due to basal ganglia and thalamic astrocytomas. ${ }^{6-20}$ This study deals with the clinical course and the change and outcome of MDs in relation to treatment of either the tumour responsible for them or of the symptomatic MDs themselves in twenty patients with basal ganglia and thalamic astrocytomas grade I-IV presenting with $\mathrm{MDs}$ at the time of biopsy.
Methods

A total of 225 patients had astrocytomas grades I-IV of the basal ganglia or the thalamus confirmed histologically by stereotactic biopsy between 1965-86 in the department of stereotaxy. Twenty were identified as having an $M D$ at the time of biopsy. ${ }^{5}$ The patients were followed up and examined at various times with recent follow ups in 1989,90 or 91. No follow up data concerning the tremor in patient 16 could be obtained. Some patients had serial film recordings over the years. Most of the long term surviving patients returned at regular intervals for control CT scans. In addition, the relatives, attending physicians and neurologists were interviewed to compile the data.

Stereotactic biopsy was performed under local anaesthesia, except in the younger children. Tumour site, volume and the irradiation dosimetry were determined from CT data available since 1975. The RiechertMundinger stereotactic device in the computer-compatible version was used for stereotactic biopsy, interstitial implantation of radioactive isotopes, cyst aspiration and functional stereotactic surgery. The principles and methods are described in detail elsewhere. ${ }^{21-26}$ The decision whether or not to perform interstitial radiotherapy was made according to the clinical state of the patient, the tumour size and the results of the intraoperative smear preparation. The presence of an MD was not relevant. Interstitial radiotherapy was performed in the same session via the puncture track for biopsy. To produce radionecroses of the tumours the radioactive isotopes ${ }^{125} \mathrm{I}$ (half-life 60.2 days, photon energy spectrum ranging between 27 and $35 \mathrm{keV}$ ) and ${ }^{192} \mathrm{Ir}$ (half-life 74.2 days, energy spectrum ranging from 300 to $610 \mathrm{keV}$ ) were used. The peripheral tumour accumulation dose (that is, at the surface of the tumour) ranged from 90 to 120 Gy. It was exceptionally high in patient 10 (150 Gy), and low (50 Gy) in patient 3. It was generally lower in more recent years.

Shunts placed were either ventriculoatrial or ventriculoperitoneal, and if necessary, bilateral.
Results

The study consisted of eleven female and nine male patients. The age at biopsy ranged from three to 70 years (table). Demographic, clinical and neuroradiological data have been reported recently. ${ }^{5}$ Ten patients were alive on recent follow up. Follow up periods ranged 
Demographic data, treatment and follow-up of 20 patients with movement disorders in basal ganglia and thalamic astrocytomas.

\begin{tabular}{|c|c|c|c|c|c|c|c|c|c|c|}
\hline Case & $\begin{array}{l}\text { Sexl } \\
\text { Age at Biopsy } \\
\text { Age at Onset }\end{array}$ & $\begin{array}{l}\text { Movement } \\
\text { disorder }\end{array}$ & $\begin{array}{l}\text { Grade } \\
\text { of astro- } \\
\text { cytoma }\end{array}$ & Status & $\begin{array}{l}\text { Follow } \\
\text { up }\end{array}$ & $\begin{array}{l}K P S: \\
a / b\end{array}$ & $\begin{array}{l}\text { Interstitial } \\
\text { curietherapy }\end{array}$ & $\begin{array}{l}\text { Shunt } \\
\text { operation }\end{array}$ & Other treatment & $\begin{array}{l}\text { Movement disorder } \\
\text { Course-Outcome }\end{array}$ \\
\hline 1 & $M / 25 / 13$ & $\begin{array}{l}\text { Tremor, } 3-4 \mathrm{~Hz} \\
1 \text { arm: } \\
\text { rest, post, int }\end{array}$ & I & A & $12 \mathrm{y}$ & $60 / 80$ & - & $+(-12 y)$ & $\begin{array}{l}\text { Perc. radiotherapy }(-12 y) \\
\text { Stereotactic aspiration of }\end{array}$ & $\begin{array}{l}\text { Dis of tremor after } \\
\text { cyst aspiration }\end{array}$ \\
\hline 2 & $M / 3 / 3$ & $\begin{array}{l}\text { reemor, } 3-5 \mathrm{~Hz} \\
\text { 1 arm > leg: post, int } \\
\text { Athetosis, h hand: rest } \\
\text { Head tilt }\end{array}$ & I & D & $6 \mathrm{~m}$ & 80 & $\mathrm{I}-125$ & $+(4 \mathrm{~m})$ & Perc, radiotherapy $(-4 \mathrm{~m})$ & $\begin{array}{l}\text { Inc of athetosis }(4 \mathrm{w}) \text {, } \\
\text { temporary imp with } \\
\text { corticosteroids }(2 \mathrm{~m})\end{array}$ \\
\hline 3 & $\mathrm{M} / 50 / 44$ & $\begin{array}{l}\text { Tremor, } 3-4 \mathrm{~Hz} \\
1 \text { arm > leg: } \\
\text { rest, post, int }\end{array}$ & I & A & $8 \mathrm{y}$ & $60 / 70$ & $\mathrm{I}-125$ & - & Medication with biperiden & $\begin{array}{l}\text { Tremor unc after curie- } \\
\text { therapy, slight imp after } \\
\text { biperiden }\end{array}$ \\
\hline 4 & $F / 49 / 43$ & $\begin{array}{l}\text { Chorea } \\
\text { face bilat, } 1>r \\
1 \text { arm }>\text { leg }\end{array}$ & $\begin{array}{l}\text { II } \\
\text { II-III } \\
(8 \mathrm{~m})\end{array}$ & D & $2 \cdot 5 \mathrm{y}$ & 60 & $\begin{array}{l}\text { a: } \operatorname{Ir}-192 \\
\text { b: Ir-192 } \\
(8 \mathrm{~m})\end{array}$ & - & $\begin{array}{l}\text { Perc, radiotherapy }(-4 y) \\
\text { Medication with haloperidol } \\
(8 \mathrm{~m})\end{array}$ & $\begin{array}{l}\text { a: Inc of hemichorea }(6 \mathrm{~m}) \\
\text { b: } 2 \mathrm{w} \text { after } 2 \text { nd stereotactic } \\
\text { operation imp of chorea with } \\
\text { haloperidol, dis } 2 \mathrm{w} \text { later }\end{array}$ \\
\hline 5 & $F / 70 / 70$ & Parkinsonism & IV & D & $1 \mathrm{~m}$ & 40 & - & $+(-1 w)$ & - & Parkinsonian symptoms unc \\
\hline 6 & $\mathrm{M} / 37 / 31$ & $\begin{array}{l}\text { Tremor, } 4-5 \mathrm{~Hz} \\
1 \text { arm: } \\
\text { rest, post, int }\end{array}$ & II & D & $4 y$ & 60 & - & & - & $\begin{array}{l}\text { Fluctuation of intensity of } \\
\text { tremor, presumably related } \\
\text { to medication with cortico- } \\
\text { steroids }\end{array}$ \\
\hline 7 & $F / 11 / 10$ & $\begin{array}{l}\text { Dystonia } \\
1 \text { arm: } \\
\text { rest, on action }\end{array}$ & I & A & $9 y$ & $60 / 70$ & I-125 & $+(-3 \mathrm{~m})$ & $\begin{array}{l}\text { Stereotactic aspiration } \\
\text { of tumour cyst (2y) } \\
\text { 2nd stereotactic aspiration } \\
\text { of tumour cyst (8y) }\end{array}$ & $\begin{array}{l}\text { Inc of hp and dystonia }(0,5-1 \mathrm{y}) \\
\text { imp of hp }+ \text { dystonia }(3 \mathrm{y}), \\
\text { inc of } h p+\text { dystonia }(6-7 \mathrm{y}) \\
\text { imp of hp }+ \text { dystonia }(8 \mathrm{y})\end{array}$ \\
\hline 8 & $M / 12 / 9$ & $\begin{array}{l}\text { Dystonia } \\
1 \text { hand: on action } \\
\text { Tremor, } 4-5 \mathrm{~Hz} \\
\text { I arm: post, int }\end{array}$ & I & A & $13 y$ & $70 / 80$ & $\begin{array}{l}\text { a: } I r-192 \\
\text { b: } I r-192 \\
(9 \mathrm{~m})\end{array}$ & $\begin{array}{l}+(1 \mathrm{w}) \\
+(2 \mathrm{y})\end{array}$ & - & $\begin{array}{l}\text { a: imp of tremor }+ \text { hp }(6 \mathrm{~m}) \text {, } \\
\text { b: unc in further course }\end{array}$ \\
\hline 9 & $M / 42 / 41$ & $\begin{array}{l}\text { Tremor, } 4 \mathrm{~Hz} \\
\text { r arm: } \\
\text { rest, post, int }\end{array}$ & II & D & $2.5 y$ & 70 & - & - & $\begin{array}{l}\text { Medication with biperiden, } \\
\text { later with metixen }\end{array}$ & $\begin{array}{l}\text { No response of tremor to } \\
\text { biperiden, imp after metixen } \\
\text { (1y), later red of tremor } \\
\text { with parallel app of hp }\end{array}$ \\
\hline 10 & $M / 25 / 25$ & $\begin{array}{l}\text { Dystonia } \\
\mathrm{r} \mathrm{arm:} \\
\text { rest, on action }\end{array}$ & I & A & $20 \mathrm{y}$ & $60 / 60$ & $\begin{array}{l}\text { a: Ir-192 } \\
\text { b: Ir-192 } \\
\text { (18y) }\end{array}$ & - & - & $\begin{array}{l}\text { a: inc of hp and dystonia } \\
\text { over years, no change in } b \text { : } \\
\text { further course }\end{array}$ \\
\hline 11 & $\mathrm{M} / 15 / 13$ & $\begin{array}{l}\text { Tremor, } 4-5 \mathrm{~Hz} \\
\text { r arm: } \\
\text { rest, post, int }\end{array}$ & I & A & $10 \mathrm{y}$ & $70 / 60$ & $\mathrm{I}-125$ & - & Various medication & $\begin{array}{l}\text { Inc of tremor after } \\
\text { thioridazine, no response to } \\
\text { trihexyphenidyl, imp after } \\
\text { biperiden, inc of } \mathrm{hp} \text {, dis of } \\
\text { tremor }(6 \mathrm{~m}) \text {, spastic } \mathrm{hp}(7 \mathrm{y})\end{array}$ \\
\hline 12 & $F / 11 / 9$ & $\begin{array}{l}\text { Chorea } \\
\mathrm{r} \text { arm > leg } \\
\text { marked on action }\end{array}$ & II & A & $21 y$ & $70 / 80$ & Ir-192 & $+(-2 y)$ & - & $\begin{array}{l}\text { Dis of chorea without inc } \\
\text { of hp }(0.5 y) \text {, no } M D \text { in } \\
\text { further course }\end{array}$ \\
\hline 13 & $F / 10 / 9$ & $\begin{array}{l}\text { Dystonia } \\
1 \text { arm }>\text { leg } \\
\text { Chorea-Ballismus } \\
1 \text { arm }>\text { leg }\end{array}$ & I & D & $5 y$ & 60 & $\begin{array}{l}\text { a: } \operatorname{Ir}-192 \\
\text { b: } \operatorname{Ir}-192(1 \mathrm{y}\end{array}$ & ${ }_{y)}^{+(4 y)}$ & - & $\begin{array}{l}\text { a: Dis of chorea }+ \text { ballismus, } \\
\text { inc of dystonia }+h p(0.5 y)\end{array}$ \\
\hline 14 & $F / 12 / 3$ & $\begin{array}{l}\text { Tremor, } 3-5 \mathrm{~Hz} \\
1 \text { arm: } \\
\text { rest, post, int }\end{array}$ & II & A & $6 y$ & $60 / 70$ & I-125 & $+(-3 \mathrm{~m})$ & - & $\begin{array}{l}\text { post shunt imp of hp, no effect } \\
\text { on tremor }(-2 \mathrm{~m}) \text {, inc of tremor } \\
(8 \mathrm{~m}) \text {, imp of tremor }+ \text { app } \\
\text { of mild dystonia arm }(2 \mathrm{y})\end{array}$ \\
\hline 15 & $M / 16 / 15$ & $\begin{array}{l}\text { Dystonia + Chorea } \\
1 \text { arm > leg > face: } \\
\text { rest, on action }\end{array}$ & IV & D & $3 d$ & 40 & - & $+(2 d)$ & - & $\begin{array}{l}\text { Postop inc of obtundation, } \\
\text { coma (possibly related to } \\
\text { inc of edema), death }\end{array}$ \\
\hline 16 & $F / 62 / 59$ & $\begin{array}{l}\text { Tremor, high- } \\
\text { frequency bilateral, } \\
1>\mathrm{r} \text { fingers }+ \text { eyelids }\end{array}$ & II & D & $6 \mathrm{~m}$ & 60 & $\mathrm{I}-125$ & - & unknown & unknown \\
\hline 17 & $F / 13 / 11$ & $\begin{array}{l}\text { Dystonia, } \mathrm{r} \text { arm: } \\
\text { rest, on action } \\
\text { Myoclonus, } \mathrm{r} \text { shoulde }\end{array}$ & $\mathrm{I}$ & D & $5 y$ & 70 & $\begin{array}{l}\text { a: Ir-192 } \\
\text { b: Gamma } \\
\text { Med (4y) }\end{array}$ & $+(4 d)$ & - & $\begin{array}{l}\text { Imp of dystonia, dis of } \\
\text { myoclonus }(2 y)\end{array}$ \\
\hline 18 & $F / 3 / 2$ & $\begin{array}{l}\text { Tremor, } 3-4 \mathrm{~Hz} \\
\mathrm{r} \text { arm: int }\end{array}$ & I & D & $11.5 \mathrm{y}$ & 70 & $\begin{array}{l}\text { a: Ir-192 } \\
\text { b: Ir-192 } \\
\text { (3y) } \\
\text { c: Ir-192 } \\
(10 y)\end{array}$ & $+(2 w)$ & - & a: Dis of tremor $(6 \mathrm{~m})$ \\
\hline 19 & $F / 5 / 5$ & $\begin{array}{l}\text { Dystonia, } \mathrm{r} \text { arm: } \\
\text { rest, on action }\end{array}$ & I & A & $16 y$ & $60 / 70$ & $\begin{array}{l}\text { a: Ir-192 } \\
\text { b: Ir-192 } \\
\text { (1y) }\end{array}$ & $+(1 \mathrm{y})$ & - & $\begin{array}{l}\text { a: imp of dystonia }+ \text { hp }(3 \mathrm{~m}) \text {, } \\
\text { inc of dystonia }+ \text { app of } r \\
\text { chorea }(1 \mathrm{y}), \mathrm{b} \text { : inc of } h p \\
\text { imp of dystonia, dis of chorea } \\
\text { (3y) }\end{array}$ \\
\hline 20 & $F / 12 / 10$ & $\begin{array}{l}\text { Tremor, } 3-4 \mathrm{~Hz} \\
\mathrm{r} \text { arm: int }\end{array}$ & I & A & $20 \mathrm{y}$ & $60 / 70$ & $\begin{array}{l}\text { a: } I r-192 \\
\text { b: } I r-192 \\
\text { (4y) }\end{array}$ & - & $\begin{array}{l}\text { Functional stereo- } \\
\text { tactic operation }(4 \mathrm{y}) \text {, } \\
\text { Stereotactic aspiration } \\
\text { of tumour cyst (15y) }\end{array}$ & $\begin{array}{l}\text { a: Imp of hp }+ \text { tremor }(1 \mathrm{y}) \text {, } \\
\text { inc of hp }+ \text { tremor }(3 y) \text {, } \\
\text { b: dis of tremor after } \\
\text { functional stereotactic } \\
\text { operation, no recurrence of } \\
\text { tremor }\end{array}$ \\
\hline
\end{tabular}

Sex: $M=$ male, $F=$ female. $R=$ right, $L=$ left. Tremor: is qualified as: rest - tremor at rest, post - postural tremor and int - intention tremor. Status: $\mathrm{A}=$ alive (at last follow up available), $\mathrm{D}=$ dead. Follow up: is defined as time of survival after stereotactic biopsy at last follow up or until death. KPS (Karnofsky Performance Scale): a: preoperative/b: at last follow-up. All intervals of time refer to stereotactic biopsy: $d=d a y s, w=w e e k s, m=m o n t h s, ~ y=y e a r(s),-=$ prior

Movement Disorder Course - Outcome: $\mathrm{hp}=$ hemiparesis, app = appearance, inc = increase, unc = unchanged, imp = improvement, red $=$ reduction, dis $=$ disappearance.

from 6-21 years (mean 13.5 years). There were no post operative complications except in patient 15. This 16 year old boy with a thalamic glioblastoma extending to the upper brainstem was in a poor condition when referred. He deteriorated further after biopsy and died three days later, probably due to an increase in intracranial pressure. In the other patients survival ranged from one month to
21 years after biopsy. In two patients anaplastic transformation was found on rebiopsy. Only patients with low-grade astrocytomas survived more than five years. With the exception of case 11, all patients who were alive on recent follow up were stable or had improved Karnofsky Performance Scores. ${ }^{27}$

MDs in this selected group of patients changed over long periods of time. In most 


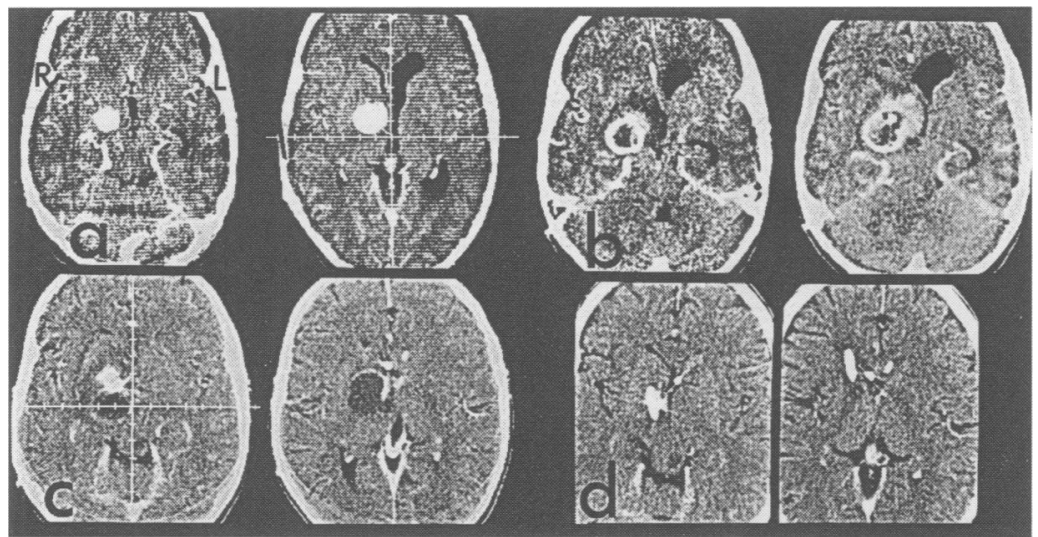

Figure 1 Axial enhanced CT scans of patient 7 with dystonia of the left arm due to a grade I astrocytoma located predominantly in the right pallidum and subthalamic region. The patient has a second tumour extending from the quadrigeminal plate to the pons and cerebellum. a) Before interstitial radiocurietherapy. b) 8 months after implantation of a ${ }^{125}$ I seed a cyst developed. c) 18 months after interstitial radiotherapy the cyst enlarged. At that time, dystonia and hemiparesis had increased further. d) 24 months after interstitial radiotherapy the cyst was aspirated stereotactically and a drainage was placed. The dystonia and the hemiparesis improved significantly.

cases these changes were temporally related to therapeutic interventions (as described below), or to recurrence or regrowth of tumour as diagnosed neuroradiologically.

Increase of hemiparesis was associated with reduction of the $M D$ in patients 9,11 and 19. However, in other patients a parallel improvement of the hemiparesis and the MD could be observed (cases 7,8 ), or conversely a parallel increase of the hemiparesis and worsening of the $\mathrm{MD}$ (cases 10,13).

\section{OUTCOME IN RELATION TO TYPE OF MOVEMENT DISORDER}

The overall outcome of the $\mathrm{MD}$ at the last follow up, without respect to therapeutic strategies, was as follows: hemichorea and hemichorea/ballismus disappeared in three patients (cases 4, 12, 13); myoclonus disappeared in one (case 17); tremor disappeared in three patients (cases $1,18,20$ ), improved to some degree in five (cases $3,8,9,11,14$ ), fluctuated in one (case 6), and did not change in two (cases 2,5 ); hemidystonia improved to some degree in three patients (cases 7,17 , 19), fluctuated in one (case 2), did not change in one (case 8), and worsened in two (cases 10,13 ). In patient 14 with a grade II astrocytoma of the right thalamus extending to the midbrain, contralateral tremor improved two years after interstitial radio-

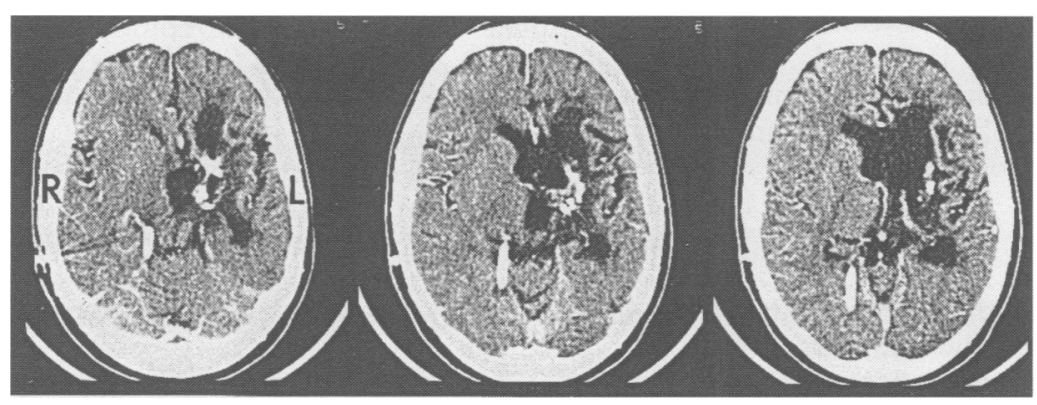

Figure 2 Axial enhanced CT scans of patient 19, 14 years after interstitial radiotherapy with ${ }^{192} \mathrm{Ir}$. The patient had presented with dystonia of the right arm due to a grade I astrocytoma of the left thalamus and basal ganglia. She also had transient right hemichorea. The CT scans demonstrate the late effects of radionecrosis with metallic artefacts of the ${ }^{192}$ Ir wires, calcifications and gliosis. There is no evidence of residual tumour. therapy, however, over this period hemidystonic postures appeared. Transient hemichorea was observed one year after interstitial radiotherapy in patient 19 .

\section{OUTCOME IN RELATION TO TREATMENT} MODALITY

In no patient was partial or radical tumour resection attempted.

Interstitial radiotherapy This was done in 15 patients. 6 were implanted twice, one patient on three occasions. During the first 3-12 months after interstitial radiotherapy, the $\mathrm{MD}$ increased, at least temporarily, in some patients (cases $2,4,7,10,14$ ). CT scans showed signs of radionecrosis with varying degrees of perifocal white matter oedema (fig 1), depending on the dose and the isotope applied. Twelve to 24 months after the operation, the MD had subsequently improved in patients 7 and 14 to be less severe than preoperatively. However, in other patients who also had signs of radionecrosis on CT controls, the $\mathrm{MD}$ improved (cases 8 , $17,19,20)$ or even disappeared during the first months following interstitial radiotherapy (cases 11, 12, 17, 18). In three patients a later increase of the $\mathrm{MD}$ indicated tumour recurrence or cyst formation (cases 7, 19, 20 ). In patient 10 with a grade I astrocytoma located mainly in the left lenticulostriate area, hemidystonia increased over many years after interstitial radiotherapy. CT controls did not show local tumour recurrence; however, a porencephalic defect had developed in the region where the tumour was previously located. No signs of tumour recurrence on the last follow up were found in patients 3 , $11,12,14,19$ and 20 (fig 2). The $M D$ was no longer present in three of them (cases 11 , $12,20)$ and had improved in three others (cases 3,14,19/ case 14 developing hemidystonia).

Functional stereotactic surgery The right intention tremor and hemiparesis of patient 20 (grade I astrocytoma of the left thalamus extending to subthalamus and crus cerebri) which had improved one year after interstitial radiotherapy with ${ }^{192} \mathrm{Ir}$ worsened again considerably on tumour regrowth after three years. One year later a stereotactic biopsy from the centre of the tumour, which was located more posteriorly in the thalamus, verified tumour recurrence, and another course of interstitial radiotherapy with ${ }^{192} \mathrm{Ir}$ was given. A biopsy was then taken from the left zona incerta, which did not show tumour cells. Following electrical stimulation, two electrocoagulations were done at the site of the biopsy in the zona incerta. The tremor had disappeared completely postoperatively and did not recur.

Stereotactic aspiration of tumour cysts Two patients had tumour cysts aspirated. Patient 1 had a left 3-4 $\mathrm{Hz}$ resting, postural and intention tremor, which disappeared completely after aspiration of a right thalamic tumour cyst extending to the midbrain and did not recur during the 12 year period of follow up (fig 3). Patient 7 showed improvement of left hemiparesis and hemidystonia after aspiration 


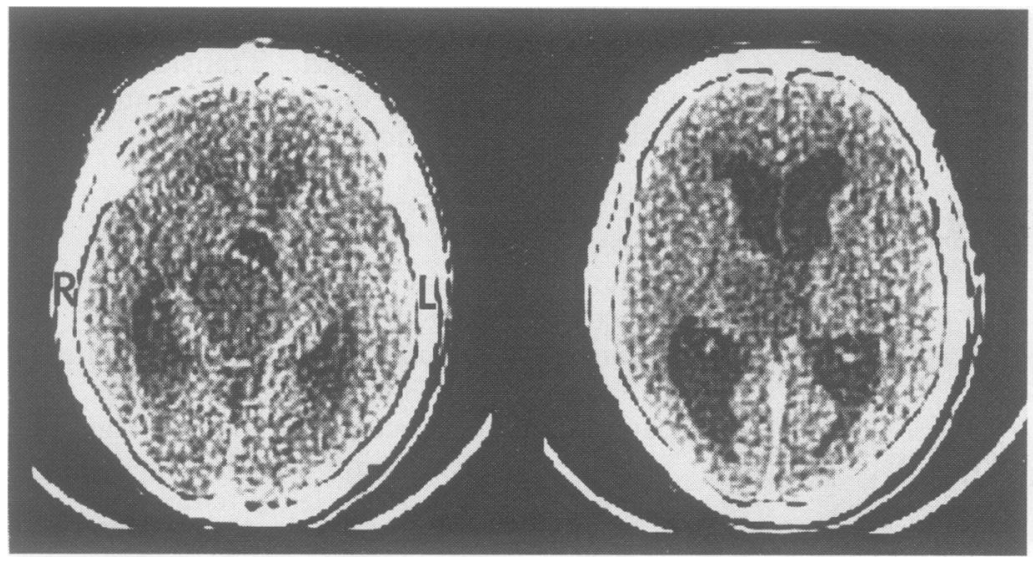

Figure 3 Axial enhanced CT scans of patient 1 who presented with left resting, postural and intention 3-4 Hz tremor show a cystic pilocytic grade I astrocytoma located in the right thalamus. The tremor disappeared after stereotactic aspiration of the tumour cyst.

of a tumour cyst located mainly in the right pallidum and subthalamus two years after interstitial radiotherapy (fig 1 ). The same effect was achieved six years later.

Percutaneous radiotherapy Three patients had undergone external beam radiation before biopsy. Patients 1 and 4 had no MD at that time and in patient 2 no obvious alterations were noted.

CSF shunts In 12 patients enlarged ventricles were shunted at some time during their disease. Three patients had had no MD when the shunt was placed and in six patients no effect on MDs was observed. A positive effect of shunting may not be excluded totally in two patients with hemidystonia and one with tremor, though improvement was more probably related to interstitial radiotherapy. Multiple revisions of shunts had no influence on $\mathrm{MDs}$ in seven patients (cases $1,5,7,8$, $12,17,19$ ).

Pharmacological trials It was difficult to assess the response to drugs. Many patients took corticosteroids for some time during the course of their disease. In patient 6 with a large diffuse low-grade astrocytoma of the right thalamus, basal ganglia and hemisphere fluctuation in intensity of tremor was related to the dose of corticosteroids. Patient 2 with a mainly thalamic grade I astrocytoma showed a slight improvement in athetosis after corticosteroid therapy. Tremor improved slightly in patients 3 and 11 after treatment with biperiden, whereas no effect on tremor was noted in patient 9 , who improved after taking metixen. Tremor increased after thioridazine in patient 11 . Chorea in patient 4 with a right frontocaudate astrocytoma improved two weeks after the second course of interstitial radiotherapy while she took haloperidol and disappeared completely two weeks later.

\section{Discussion}

The majority of patients with MDs secondary to basal ganglia and thalamic tumours collected from the literature were reported more than three decades ago, most of them having had open surgery. Operations performed were described as subtemporal decompression, ${ }^{67}$ exploration, ${ }^{67}$ open biopsy, ${ }^{1018}$ partial resec- tion, 68913 "paleating operation", and total extirpation. ${ }^{12}$ Regardless of which technique was applied, the results in general were poor and the majority of patients died within two months after operation, many of them in the first postoperative days. There are no previous reports on long term follow up, and few data on the subsequent evolution of the MDs. Disappearance or relief of the MD postoperatively was reported after partial resection of tumours affecting parts of the hemisphere and the basal ganglia in three patients: remission of Parkinsonian symptoms, ${ }^{13}$ marked decrease of intention tremor ${ }^{6}$ and disappearance of tremor and rigidity. ${ }^{9}$ One recent patient with a frontotemporal astrocytoma grade I had temporary improvement of hemidystonia after a frontal lobectomy. ${ }^{15}$ "Disappearance" of dystonia or choreoathetosis was also reported after removal of basal ganglia or thalamic astrocytomas, but those patients were hemiplegic postoperatively. ${ }^{112}$ In two patients with tremor, stereotactic resection of a low-grade astrocytoma of the thalamus was performed ${ }^{1}$ ${ }^{16}$ resulting in mild improvement of tremor six months later in one of them. ${ }^{16}$

Functional stereotactic surgery was only rarely carried out in patients with $\mathrm{MDs}$ due to tumours or secondary to treatment of tumour. ${ }^{28-30}$ To our knowledge, its use has never been described in a patient with symptomatic $\mathrm{MD}$ due to a thalamic astrocytoma. Shunt operations have been reported to alter MDs in patients with hydrocephalus. ${ }^{31} 32$ However, there was no unequivocal effect on the MDs after shunt operations in the present series. For most previously reported cases, the effect of percutaneous radiotherapy on the MD was either not recorded or was doubtful.81012171820 In two patients with hemidystonia due to contralateral tumours of the basal ganglia the MD was reported to have improved to some degree after percutaneous irradiation. ${ }^{15} 19$

Experience with medication for MDs secondary to astrocytomas of the basal ganglia and the thalamus is very limited. Apart from one report stating that anti-Parkinsonian drug therapy had no benefit on Parkinsonian symptoms in a 62 year old male with a grade II astrocytoma of the thalamus, ${ }^{14}$ we found no other remarks on the effects of drug therapy on tremor. No data are available from the literature on medical treatment of chorea or "choreoathetosis". Moderate improvement of hemidystonia after carbamazepine was described in an eight year old boy with a contralateral low-grade astrocytoma located mainly in the putamen and pallidum. ${ }^{19}$

We could not find previous reports on the effect of interstitial radiotherapy on MDs in astrocytomas of the basal ganglia and the thalamus, which as demonstrated, may have complex effects on the later evolution of the MDs.

Interpretation of the data on alterations of MDs in patients with tumours of the basal ganglia and the thalamus-particularly the alterations after interstitial radiotherapyneeds to consider different variables that may 
have either synergistic or opposing actions in an individual patient, and thus produce completely different results. We have proposed that MDs in those patients might result from structural lesions as well as from functional damage of structures involved primarily by the tumour ("internal" compression) or of adjacent regions ("external" compression). 533 These interactions may account particularly for the change of MDs in patients who had treatment resulting in modifications of local pressure. Thus, for example, disappearance of tremor in patient 1 after decompression by aspiration of the thalamic tumour cyst probably results from reducing "external" compression on afferent thalamic pathways, and the amelioration of hemidystonia in patient 7 after aspiration of the tumour cyst located mainly in the pallidum and subthalamus might be the result of reducing "external" compression on the thalamus and/or the putamen.

The "internal" or "external" involvement of structures of the basal ganglia known to reduce MDs when lesioned or stimulated (that is, the target points of functional stereotactic surgery) may also change over time in a patient. Interstitial radiotherapy produces sharply delineated radionecrosis with a perifocal zone of demyelination, gliosis and vasogenic oedema, depending on the radioisotope and the dose applied. ${ }^{34-36}$ These sequelae may be responsible for the decrease as well as for the increase of the MDs by changing the degree of "internal" and "external" compression on relevant structures.

In those patients who had no neuroradiological signs of tumour regrowth or recurrence later on, the $\mathrm{MD}$ became more or less stable after some years. The residual structural lesions of the basal ganglia and the thalamus after interstitial radiotherapy corresponded to the established clinicopathological correlations between the site of the lesion and the resulting MD. 5153738

The severity of MDs, which may occur together with corticospinal tract dysfunction, is usually inversely related to the severity of the hemiparesis. It is therefore not surprising that MDs may "disappear" in hemiplegia. ${ }^{11} 12$ However, in individual patients with basal ganglia or thalamic tumours there may be different changes in pressure on the corticospinal tract and on "extra-pyramidal" nuclei and pathways, especially after interstitial radiotherapy, depending on the localisation and the extent of the tumour and on the reaction to radiation.

Movement disorders in most patients with astrocytomas of the basal ganglia and the thalamus are subject to change in the long term. Their evolution is more dynamic than that of other MDs secondary to basal ganglia lesions being influenced by therapeutic interventions and the growth or regrowth of the tumours.

Although symptomatic medical or surgical measures may sometimes alleviate the $\mathrm{MD}$, treatment should primarily be directed to the neoplasm causing the $\mathrm{MD}$.
We thank G Pfister, H Förster, K Roskamm and V SonntagO'Brien for technical assistance and preparation of the manuscript.

1 Kelly PJ. Stereotactic biopsy and resection of thalamic astrocytomas. Neurosurgery 1989;25:185-95.

2 Bernstein M, Hoffman HJ, Halliday WC, Hendrick EB, Humphreys RB. Thalamic tumors in children. $f$ Neurosurg 1984;61:649-56.

3 McKissock W, Paine KWE. Primary tumours of the thalamus. Brain 1958;81:41-63.

4 Tovi D, Schisano G, Liljequist B. Primary tumors of the region of the thalamus. $\mathcal{F}$ Neurosurg $1961 ; 18: 730-40$.

5 Krauss JK, Nobbe F, Wakhloo AK, Mohadjer M, Vach W, Mundinger F. Movement disorders in astrocytomas of the basal ganglia and the thalamus. 7 Neurol Neurosurg Psychiatry 1992;55:1162-7.

6 Ody F. Tumors of the basal ganglia. Arch Neurol Psychiatr 1932;27:249-69.

7 Globus JH, Kuhlenbeck H. Tumors of the striatothalamic and related regions. Arch Pathol 1942;34:674-734.

8 Roth RL, Bebin J. Cerebral hemispheric tumors and extrapyramidal signs and symptoms. Neurology 1958;8: 277-84.

9 Tolosa E, Vilato J, Fuenmayor P. Parkinsonisme tumoral. Neurochirurgie 1966;12:555-60.

10 Cheek WR, Taveras JM. Thalamic tumors. $f$ Neurosurg 1966;24:505-13.

11 Arseni C, Nash F, Samitka DC. Extra-pyramidal syndromes with intracranial tumour. Psychiat Neurol 1959; 137:230-44.

12 Chorobski J. Involuntary movements in patients with intracranial tumors. Arch Neurol 1962;6:27-42.

13 Garcin R, Klein MR, Kipfer M, Bozec L. Hémisyndrome parkinsonien gauche par tumeur fronto-calleuse droite parkinsonien gauche par tumeur fronto-calleuse droite Rev Neurol 1943;3:80-3.

14 Kulali A, Tugtekin $M$, Ütkür Y, Erkurt S. Ipsilateral hemi-parkinsonism secondary to an astrocytoma. $f$ Neurol Neurosurg Psychiatry 1991;54:653.

15 Marsden CD, Obeso JA, Zarranz JJ, Lang AE. The anatomical basis of symptomatic hemidystonia. Brain 1985;108:463-83.

16 McGirr SJ, Kelly PJ, Scheithauer BW. Stereotactic resection of juvenile pilocytic astrocytomas of the thalamus and basal ganglia. Neurosurgery 1987;20:447-52.

17 Mettler FA, Davidoff LM, Grimes R. Static tremor with hemiplegia. Arch Neurol Psychiat 1947;57:423-9.

18 Millichap JG, Miller RH, Backus RE. Intracranial tumors in childhood. $Y A M A$ 1962;179:589-93.

19 Narbona J, Obeso JA, Tunon T, Martinez-Lage JM, Marsden CD. Hemi-dystonia secondary to localised Masal ganglia tumour. $\mathcal{F}$ Neurol Neurosurg Psychiatry basal ganglia

20 Sciarra D, Sprofkin BE. Symptoms and signs referrable to the basal ganglia in brain tumor. Arch Neurol Psychiat 1953;69:450-61

21 Birg W, Mundinger F. Computer calculations of target parameters for a stereotactic apparatus. Acta Neurochir 1973;29:123-9.

22 Mundinger F. CT-stereotactic biopsy for optimizing the therapy of intracranial processes. Acta Neurochir Suppl 1985;35:70-4.

23 Mundinger F, Riechert T. Die stereotaktischen Hirnoperationen zur Behandlung extrapyramidaler Bewegungsstörungen (Parkinsonismus und Hyperkinesen) und ihre Resultate. Fortschr Neurol Psych kinesen) und ihre Resu

24 Riechert T, Mundinger F. Beschreibung und Anwendung eines Zielgerätes für stereotaktische Hirnoperationen (2. Modell). Acta Neurochir 1956;3:308-37.

25 Mundinger F, Braus DF, Krauss JK, Birg W. Long-term outcome of 89 low-grade brain-stem gliomas after interstitial radiation therapy. $\mathcal{F}$ Neurosurg 1991;75:740-6.

26 Mundinger F, Sauerwein. "GammaMed", ein neues Gerät zur interstitiellen, nur einige Minuten dauernden Bestrahlung von Hirngeschwülsten mit Radioisotopen, auch intraoperativ anwendbar. Acta Radiol 1966;5: 48-52.

27 Karnofsky DA, Burchenal JH. The clinical evaluation of chemotherapeutic agents in cancer. In: MacLeod CM, ed. Evaluation of chemotherapeutic agents. New York: Columbia University Press, 1949;191-205.

28 Nittner K. Doppelseitige einzeitige stereotaktische Hirnoperation nach Hirntumoroperation. Nervenarzt 1965;36:394-7.

29 Hirai T, Miyazaki M, Nakajima H. The correlation between tremor characteristics and the predicted volume of effective lesions in stereotaxic nucleus ventralis intermedius thalamotomy. Brain 1983;106:1001-18.

30 Maeda H, Kondo T, Ohye C, Narabayashi H. Physiologically controlled VIM thalamotomy for red nucleus syndrome. Appl Neurophysiol 1979;42:310-1 (Abst)

31 Jensen F, Jensen FT. Acquired hydrocephalus. Acta Neurochir 1979;46:119-33.

32 Sypert GW, Leffman H, Ojemann GA. Occult normal pressure hydrocephalus manifested by parkinsonismdementia complex. Neurology 1973;23:234-8.

33 Krauss JK, Mohadjer M, Nobbe F, Scheremet $R$. Hemidystonia due to a contralateral parieto-occipital metastasis: disappearance after removal of the mass 
lesion. Neurology 1991;41:1519-20.

34 Groothuis DR, Wright DC, Ostertag CB. The effect of ${ }^{125 I}$ interstitial radiotherapy on blood-brain barrier function in normal canine brain. $₹$ Neurosurg 1987;67:895-902.

35 Ostertag CB, Groothuis D, Kleihues P. Experimental data on early and late morphologic effects of permanently implanted gamma and beta sources (iridium-192, iodine-125 and yttrium-90) in the brain. Acta Neurochir Suppl 1984;33:271-80.

36 Ostertag CB, Weigel K, Warnke P, Lombeck G, Kleihues
P. Sequential morphological changes in the dog brain after interstitial iodine-125 irradiation. Neurosurgery 1983;13:523-8.

37 Pettigrew LC, Jankovic J. Hemidystonia: a report of 22 patients and a review of the literature. $f$ Neurol Neurosurg Psychiatry 1985;48:650-7.

38 Krauss JK, Mohadjer M, Braus DF, Wakhloo AK, Nobbe F, Mundinger F. Dystonia following head trauma: a report of nine patients and review of the literature. Mov Disord 1992;7:263-72. 